\title{
Hypoxia differentially regulates muscle oxidative fiber type and metabolism in a HIF-1 $\alpha$-dependent manner
}

Citation for published version (APA):

Slot, I. G., Schols, A. M. W. J., Vosse, B. A., Kelders, M. C., \& Gosker, H. R. (2014). Hypoxia differentially regulates muscle oxidative fiber type and metabolism in a HIF-1a-dependent manner. Cellular Signalling, 26(9), 1837-1845. https://doi.org/10.1016/j.cellsig.2014.04.016

Document status and date:

Published: 01/01/2014

DOI:

10.1016/j.cellsig.2014.04.016

Document Version:

Publisher's PDF, also known as Version of record

Document license:

Taverne

Please check the document version of this publication:

- A submitted manuscript is the version of the article upon submission and before peer-review. There can be important differences between the submitted version and the official published version of record.

People interested in the research are advised to contact the author for the final version of the publication, or visit the DOI to the publisher's website.

- The final author version and the galley proof are versions of the publication after peer review.

- The final published version features the final layout of the paper including the volume, issue and page numbers.

Link to publication

\footnotetext{
General rights Owners
rights.

- You may freely distribute the URL identifying the publication in the public portal. please follow below link for the End User Agreement:

www.umlib.nl/taverne-license

Take down policy

If you believe that this document breaches copyright please contact us at:

repository@maastrichtuniversity.nl

providing details and we will investigate your claim.
}

Copyright and moral rights for the publications made accessible in the public portal are retained by the authors and/or other copyright owners and it is a condition of accessing publications that users recognise and abide by the legal requirements associated with these

- Users may download and print one copy of any publication from the public portal for the purpose of private study or research.

- You may not further distribute the material or use it for any profit-making activity or commercial gain

If the publication is distributed under the terms of Article $25 \mathrm{fa}$ of the Dutch Copyright Act, indicated by the "Taverne" license above, 


\title{
Hypoxia differentially regulates muscle oxidative fiber type and metabolism in a HIF- $1 \alpha$-dependent manner
}

\author{
Ilse G.M. Slot, Annemie M.W.J. Schols, Bettine A.H. Vosse, Marco C.J.M. Kelders, Harry R. Gosker* \\ Department of Respiratory Medicine, NUTRIM School for Nutrition, Toxicology and Metabolism, Maastricht University Medical Centre +, PO Box 5800, 6202 AZ Maastricht, The Netherlands
}

\section{A R T I C L E I N F O}

\section{Article history:}

Received 4 April 2014

Accepted 27 April 2014

Available online 2 May 2014

\section{Keywords:}

$\mathrm{C} 2 \mathrm{C} 12$

Fiber-type profile

Hypoxia

Oxidative phenotype

\begin{abstract}
A B S T R A C T
Loss of skeletal muscle oxidative fiber types and mitochondrial capacity is a hallmark of chronic obstructive pulmonary disease and chronic heart failure. Based on in vivo human and animal studies, tissue hypoxia has been hypothesized as determinant, but the direct effect of hypoxia on muscle oxidative phenotype remains to be established. Hence, we determined the effect of hypoxia on in vitro cultured muscle cells, including gene and protein expression levels of mitochondrial components, myosin isoforms (reflecting slow-oxidative versus fast-glycolytic fibers), and the involvement of the regulatory PPAR/PGC- $1 \alpha$ pathway. We found that hypoxia inhibits the PPAR/PGC- $1 \alpha$ pathway and the expression of mitochondrial components through HIF- $1 \alpha$. However, in contrast to our hypothesis, hypoxia stimulated the expression of slow-oxidative type I myosin via HIF- $1 \alpha$. Collectively, this study shows that hypoxia differentially regulates contractile and metabolic components of muscle oxidative phenotype in a HIF- $1 \alpha$-dependent manner.
\end{abstract}

(c) 2014 Published by Elsevier Inc.

\section{Introduction}

Hypoxia has been implicated in skeletal muscle metabolic impairments in chronic diseases such as chronic obstructive pulmonary disease (COPD) and chronic heart failure (CHF) [1-4]. Although it is generally known that hypoxia is involved in the stimulation of glycolytic metabolism through among others the hypoxia-inducible factor 1 (HIF-1) [5], a direct role for hypoxia in the downregulation of oxidative metabolism is less firmly established. Skeletal muscle of patients with COPD or CHF is characterized by an impaired oxidative phenotype, including reduced oxidative enzyme activities and a shift from oxidative to glycolytic fiber types $[1,6]$. Hypoxia has been suggested to be involved in this downregulation of muscle oxidative phenotype [1]. However, studies involving humans as well as experimental animal models resulted in inconsistent findings; i.e. loss of, unchanged or even improved muscle oxidative phenotype has been shown [7-17]. These inconsistencies are inherent to the in vivo nature of these studies in which any direct effect of hypoxia probably was confounded by indirect effects, such as hypoxia-induced changes in food intake, physical activity or circulating hormone levels. Moreover, mountain expeditions were frequently seized to study muscular adaptations to hypoxia in humans, thereby however certainly introducing strenuous exercise as a confounding factor, as well

\footnotetext{
* Corresponding author. Tel.: + 3143 3884298; fax: + 31877845882.

E-mail addresses: i.slot@maastrichtuniversity.nl (I.G.M. Slot),

a.schols@maastrichtuniversity.nl (A.M.W.J. Schols), bettine.vosse@mumc.nl (B.A.H. Vosse), marco.kelders@maastrichtuniversity.nl (M.C.J.M. Kelders), h.gosker@maastrichtuniversity.nl (H.R. Gosker).
}

as disturbance of the sleep cycle, cold temperatures and the anorexic effect of altitude $[13,18,19]$.

In response to cellular hypoxia, cells are forced to limit oxygen consumption and to shift from mitochondrial respiration to glycolysis for ATP production [20]. Hypoxia-inducible factor (HIF) protein, the master regulator of the hypoxic response, is stabilized under hypoxic conditions and directly involved in the upregulation of several glycolytic enzymes to stimulate glycolytic metabolism [21]. Also, overexpression of HIF- $1 \alpha$ has been linked to a fast muscle fiber type [22]. It is however unclear whether hypoxia can reciprocally inhibit oxidative phenotype in muscle, although it has been shown that HIF- $1 \alpha$ knockout mice indeed demonstrate a modestly improved activity of oxidative enzymes [23].

Master regulators of oxidative phenotype are the peroxisome proliferator-activated receptors (PPARs) and specifically the PPAR $\gamma$ coactivator-1 family (PGC-1s) [24,25]. PGC-1s coactivate not only PPARs, but also estrogen-related receptors (ERRs) and nuclear respiratory factors (NRFs), to stimulate mitochondrial biogenesis and oxidative capacity $[26,27]$. Decreased expression levels of PPARs and PGC- $1 \alpha$ have indeed been shown in skeletal muscle of COPD patients [28] and rats with CHF [29], suggesting potential involvement of these factors in the loss of oxidative capacity.

In this study, we investigated the direct effect of hypoxia on oxidative phenotype in an in vitro model of muscle fibers (myotubes) and the role of HIF- $1 \alpha$ herein. We hypothesized that hypoxia impairs muscle oxidative phenotype in a HIF- $1 \alpha$-dependent manner by downregulating the PPAR/PGC- $1 \alpha$ pathway, either through direct targeting of the PPARs or by influencing expression or activity of PPAR co-regulators. 


\section{Materials and methods}

\subsection{Chemicals, reagents and materials}

All reagents used were analytical grade. Tricine, glycine, sodium chloride $(\mathrm{NaCl})$, potassium chloride $(\mathrm{KCl})$, disodium hydrogen phosphate $\left(\mathrm{Na}_{2} \mathrm{HPO}_{4}\right)$, monopotassium phosphate $\left(\mathrm{KH}_{2} \mathrm{PO}_{4}\right)$, magnesium sulfate $\left(\mathrm{MgSO}_{4}\right)$, magnesium carbonate $\left(\left[\mathrm{MgCO}_{3}\right]_{4} \mathrm{Mg}[\mathrm{OH}]_{2} \cdot 5 \mathrm{H}_{2} \mathrm{O}\right)$ and cobalt chloride $\left(\mathrm{CoCl}_{2}\right)$ were obtained from Merck (Roden, The Netherlands). Tris, methanol, ethylenediaminetetraacetic acid (EDTA), sodium dodecyl sulfate (SDS), glycerol, nonidet P40, sodium orthovanadate $\left(\mathrm{Na}_{3} \mathrm{VO}_{4}\right)$, dithiothreitol (DTT), phenylmethylsulfonyl fluoride (PMSF), leupeptin, aprotinin, bromophenol blue, coenzyme A, dimethyl sulfoxide (DMSO), and bovine serum albumin (BSA) were from Sigma (Zwijndrecht, The Netherlands). ATP was purchased from Roche (Woerden, The Netherlands) and GW-501516 from Alexis Biochemicals (Lausen, Switzerland).

Cell culture flasks and stripettes were from Corning Life Sciences BV (Schiphol-Rijk, The Netherlands) and culture dishes from BD Falcon (Breda, The Netherlands). Fetal bovine serum (FBS), penicillin/ streptomycin and Hank's Buffered Salt Solution (HBSS; calcium-, magnesium- and phenol red-free) were from PAA Laboratories (Pasching, Germany). Dulbecco's Modified Eagle's Medium (DMEM) was purchased from Invitrogen (Breda, The Netherlands) and Matrigel from BD Biosciences (San Jose, CA, USA). TNF- $\alpha$ was obtained from Calbiochem (Nottingham, United Kingdom) and dissolved in 0.1\% BSA. Reporter Lysis $5 \times$ Buffer and beetle luciferin potassium salt for luciferase reporter assays were from Promega (Leiden, The Netherlands).

\subsection{Cell culture}

The in vitro model for assessing the effect of hypoxia on muscle consisted of myotubes that were exposed for some hours up to several days to hypoxic conditions. Murine skeletal muscle C2C12 cells were obtained from the American Tissue Culture Collection (ATCC, no. CRL-1772; Manassas, VA, USA). Myocytes were cultured in growth medium consisting of low glucose DMEM, $9 \%(\mathrm{v} / \mathrm{v})$ FBS, $45 \mathrm{U} / \mathrm{ml}$ penicillin and $45 \mu \mathrm{g} / \mathrm{ml}$ streptomycin in a $37{ }^{\circ} \mathrm{C}$ incubator with $5 \% \mathrm{CO}_{2}$. Cells were seeded on Matrigel-coated $35-\mathrm{mm}$ dishes at a density of $4 \cdot 10^{4}$ cells $/ \mathrm{cm}^{2}$ and grown to $\pm 80 \%$ confluency after which differentiation was induced by two washes with HBSS and addition of differentiation medium (DMEM, 1\% [v/v] heat-inactivated FBS [30 min at $56{ }^{\circ} \mathrm{C}$ ], $50 \mathrm{U} / \mathrm{ml}$ penicillin and $50 \mu \mathrm{g} / \mathrm{ml}$ streptomycin). After 5 days myotubes were fully differentiated and used for the actual experiments. For hypoxic conditions, myotubes were placed in a hypoxic incubator with $4 \% \mathrm{O}_{2}, 5 \% \mathrm{CO}_{2}$ and $91 \% \mathrm{~N}_{2}$ for $24 \mathrm{~h}$ up to 3 days, depending on the type of experiment.

\subsection{Luciferase reporter assays}

To assess the effect of hypoxia on the transcriptional activity of HIF, PPAR and NF- $\kappa B$ transcription factors, C2C12 cells were stably transfected with luciferase reporter plasmids sensitive to HIF (HIF reporter), PPAR (PPAR reporter) or NF- $\kappa \mathrm{B}(\mathrm{NF}-\kappa \mathrm{B}$ reporter), respectively. The HIF reporter expresses the luciferase gene controlled by a promoter bearing five consecutive hypoxia-inducible factor (HIF) responsive elements (HREs) from the human vascular endothelial growth factor A (VEGFA) promoter (5HRE/hCMVmp-luc [30]) and was kindly provided by Dr. Twan van den Beucken (Maastricht University, The Netherlands). As a positive control, HIF- $1 \alpha$ was stabilized under normoxic conditions by adding $\mathrm{CoCl}_{2}$ to a final concentration of $150 \mu \mathrm{M}$. The PPAR reporter promoter contains the peroxisome proliferator-activated receptor (PPAR)-responsive element from the human carnitine palmitoyltransferase 1B promoter (MCPT.Luc.1025 [31]) and was a gift from Dr. Marc van Bilsen

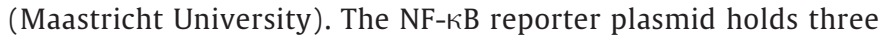

repeats of the human immunodeficiency virus type 1 (HIV-1) tandem NF- $\kappa$ B sites in front of a minimal thymidine kinase (TK) promoter $(6 \times \kappa B-t k$ Luc [32]) and was kindly provided by Dr. Patrick Baeuerle (Micromet, Germany). As a positive control, NF-kB transcriptional activity was stimulated by adding TNF- $\alpha$ to selected dishes at $10 \mathrm{ng} / \mathrm{ml}$. BSA was added to dishes to a final concentration of $0.005 \%$ as a vehicle control for the TNF- $\alpha$ treated dishes.

To assess treatment-associated expression of luciferase, myotubes were harvested by washing twice with cold phosphate-buffered saline (PBS; $137 \mathrm{mM} \mathrm{NaCl}, 2.7 \mathrm{mM} \mathrm{KCl}, 10.1 \mathrm{mM} \mathrm{Na}_{2} \mathrm{HPO}_{4}, 1.8 \mathrm{mM} \mathrm{KH}_{2} \mathrm{PO}_{4}$, $\mathrm{pH} 7.4$ ) and lysis in Reporter Lysis $5 \times$ Buffer by scraping with a rubber policeman and freezing at $-80{ }^{\circ} \mathrm{C}$. After thawing, insoluble material was spun down in $2 \mathrm{~min}$ at $20000 \times \mathrm{g}$ and the soluble fraction was used for luciferase activity assay. Samples were analyzed on a singletube luminometer with injector (LB9507, Berthold Technologies, Bad Wildbad, Germany) to add Luciferase Assay Reagent (20 mM Tricine, $1.07 \mathrm{mM}\left[\left(\mathrm{MgCO}_{3}\right)_{4} \mathrm{Mg}(\mathrm{OH})_{2} \cdot 5 \mathrm{H}_{2} \mathrm{O}\right], 2.67 \mathrm{mM} \mathrm{MgSO}_{4}, 0.1 \mathrm{mM}$ EDTA, $33.3 \mathrm{mM}$ DTT, $270 \mu \mathrm{M}$ coenzyme $\mathrm{A}, 470 \mu \mathrm{M}$ beetle luciferin potassium salt and $580 \mu \mathrm{M}$ ATP, pH 7.8) to the sample. Luciferase activities were expressed relative to protein concentration in the soluble fraction as measured by Bio-Rad Protein Assay (Bio-Rad, Veenendaal, The Netherlands) in a microtiter plate according to the manufacturer's protocol.

\subsection{RNA extraction and $q R T-P C R$ analysis}

RNA was extracted using the RNeasy Plus Mini Kit (Qiagen, Venlo, The Netherlands) with gDNA eliminator spin columns to remove genomic DNA according to the manufacturer's protocol. After elution, RNA concentration was determined using a spectrophotometer (NanoDrop ND-1000, Isogen Lifescience, IJsselstein, The Netherlands) and integrity verified for a selection of samples by gel electrophoresis.

400 ng RNA was reverse transcribed to cDNA with a mix of anchored oligo(dT) and random hexamer primers according to the supplier's protocol (Transcriptor First Strand cDNA Synthesis kit, Roche Diagnostics, Woerden, The Netherlands). Quantitative reverse-transcription PCR (qRT-PCR) primers were based on Ensembl [33] transcript sequences and designed intron-spanning if possible. Primers were ordered from Sigma Genosys (Zwijndrecht, The Netherlands) (Tables 1 and 2). For relative quantification, standard curves were prepared from pooled neat cDNA aliquots of all samples by five serial five-fold dilutions. cDNA samples were diluted 1/50 and for both standards and samples, $5 \mu$ diluted cDNA was loaded in a Hard-Shell Full-Height 96-Well Semi-Skirted PCR Plate (Bio-Rad) covered with Microseal 'B' adhesive seals (Bio-Rad). cDNA was amplified with SensiMix SYBR \& Fluorescein Kit (Quantace-Bioline, London, UK) supplemented with $300 \mathrm{nM}$ primers on a Bio-Rad MyiQ thermocycler (Bio-Rad). Two-step PCR was performed with the following cycling conditions: 10 min at $95^{\circ} \mathrm{C}, 40$ cycles of $10 \mathrm{~s}$ at $95^{\circ} \mathrm{C}$ and $15 \mathrm{~s}$ at $60^{\circ} \mathrm{C}$ and then $30 \mathrm{~s}$ at $95^{\circ} \mathrm{C}$ and $30 \mathrm{~s}$ at $60{ }^{\circ} \mathrm{C}$, followed by a melting curve (heating from $60{ }^{\circ} \mathrm{C}$ to $95^{\circ} \mathrm{C}$ with $10 \mathrm{~s}$ per $0.5^{\circ} \mathrm{C}$ increase). Standard curves and melt curves were analyzed to verify efficiency and specificity of amplification. Five reference genes (Axin1, B2m, Canx, Ppia and Rplp0) were measured and stability of expression was assessed by visual inspection of expression differences between the study conditions and a stability assessment by geNorm [34]. Stable genes were included to calculate a normalization factor to normalize expression levels of the other measured target genes.

\subsection{Western blot analysis}

Cells were washed twice with ice-cold PBS followed by 10 min incubation in lysis buffer (20 mM Tris, $150 \mathrm{mM} \mathrm{NaCl}, 1 \%$ (v/v) nonidet P40, 1 mM DTT, 1 mM Na$V_{3} V_{4}, 1$ mM PMSF, $10 \mu \mathrm{g} / \mathrm{ml}$ leupeptin, 1\% (v/v) aprotinin, $\mathrm{pH} 7.4)$ on ice. Cells were scraped with rubber policemen and lysates were incubated for $30 \mathrm{~min}$ on a rotating wheel at $4{ }^{\circ} \mathrm{C}$. Insoluble contents were precipitated during $30 \mathrm{~min}$ centrifugation 
Table 1

qRT-PCR primer details for reference genes.

\begin{tabular}{|c|c|c|c|c|c|}
\hline Symbol & Name & Ensembl ID & $\begin{array}{l}\text { Forward primer } \\
\left(5^{\prime} \rightarrow 3^{\prime}\right)\end{array}$ & $\begin{array}{l}\text { Reverse primer } \\
\left(5^{\prime} \rightarrow 3^{\prime}\right)\end{array}$ & $\begin{array}{l}\text { Amplicon } \\
\text { size (bp) }\end{array}$ \\
\hline Axin1 & Axin 1 & ENSMUSG00000024182 & AGTGGATCATTGAGGGAGAGA & GCCCCAGGACGCTCGAT & 124 \\
\hline$B 2 m$ & Beta-2-microglobulin & ENSMUSG00000060802 & CTTTCTGGTGCTTGTCTCACTGA & GTATGTTCGGCTTCCCATTCTC & 104 \\
\hline Canx & Calnexin & ENSMUSG00000020368 & GCAGCGACCTATGATTGACAACC & GCTCCAAACCAATAGCACTGAAAGG & 170 \\
\hline Ppia & $\begin{array}{l}\text { Peptidyl-prolyl cis-trans isomerase } \\
\text { A; cyclophilin A }\end{array}$ & ENSMUSG00000071866 & TTCСТССТTТСАСАGAATTATTCCA & CCGCCAGTGCCATTATGG & 75 \\
\hline Rplp0 & Large ribosomal protein P0 & ENSMUSG00000067274 & GGACCCGAGAAGACCTCCTT & GCACATCACTCAGAATTTCAATGG & 85 \\
\hline
\end{tabular}

at $20000 \times g$ at $4{ }^{\circ} \mathrm{C}$. A small volume of soluble fraction was kept for protein assay and the rest diluted in $4 \times$ sample buffer $(0.25 \mathrm{M}$ Tris, $8 \%(\mathrm{w} / \mathrm{v}$ ) SDS, $40 \%$ glycerol, 0.4 M DTT, 0.02\% bromophenol blue, pH 6.8) and boiled for 5 min at $95{ }^{\circ} \mathrm{C}$. Per sample, $20 \mu \mathrm{g}$ protein was separated on gel (4-12\% Bis-Tris XT gel, Criterion, Bio-Rad) with XT MOPS running buffer (Bio-Rad). Proteins were transferred to a $0.45 \mu \mathrm{m}$ nitrocellulose membrane (Protran, Schleicher and Schuell, 's-Hertogenbosch, The Netherlands) in transfer buffer (25 mM Tris, $192 \mathrm{mM}$ glycine, 20\% (v/v) methanol) by electrophoresis for $3 \mathrm{~h}$ at $30 \mathrm{~mA}$ and $4{ }^{\circ} \mathrm{C}$. After transfer, membranes were blocked from nonspecific protein binding with 5\% non-fat dry milk (Campina, Eindhoven, The Netherlands) in Tris-buffered saline (TBS; $25 \mathrm{mM}$ Tris, $137 \mathrm{mM} \mathrm{NaCl}, 2.7 \mathrm{mM} \mathrm{KCl}$, $\mathrm{pH} 7.4$ ) with $0.05 \%$ Tween 20 (TBST) in $1 \mathrm{~h}$ at room temperature, followed by incubation in primary antibody overnight at $4{ }^{\circ} \mathrm{C}$ (mouse antimyosin slow (M8421, Sigma), mouse anti-myosin fast (M4276, Sigma), mouse anti-Total OXPHOS Rodent WB Antibody Cocktail (MS604-300, MitoSciences, Eugene, OR, USA), rabbit anti-GAPDH (\#2118, Cell Signaling Technology, Beverly, MA, USA), or mouse anti$\alpha$-tubulin (T6074, Sigma) diluted in 5\% BSA (Sigma) in TBST). Membranes were incubated in secondary antibody solutions (peroxidaselabeled horse anti-mouse IgG [Vector Laboratories, Burlingame, CA, USA] in 5\% non-fat dry milk in TBST) during $3 \mathrm{~h}$ at room temperature before incubation with enhanced chemiluminescence substrate (Pierce SuperSignal West PICO Chemiluminescent Substrate; Thermo Fisher Scientific, Breda, The Netherlands). Protein bands were detected using Super RX films (Fujifilm, Düsseldorf, Germany) and scanned on a GS-800 densitometer (Bio-Rad). Bands were quantified using Quantity One software (v4.6.2, Bio-Rad), with GAPDH or $\alpha$-tubulin as loading control. Equal GAPDH or $\alpha$-tubulin content in normoxic compared to hypoxic samples was verified before correction of the other protein targets.

\subsection{Transient knockdown of HIF-1 $\alpha$ gene expression}

To study the role of HIF- $1 \alpha$ in the response of oxidative capacity to hypoxia, the gene expression of HIF- $1 \alpha$ was knocked down by RNA interference. Four-day old myotubes were transfected with Stealth RNAi siRNA for HIF-1 $\alpha$ (MSS205126, Invitrogen) or Stealth RNAi Negative Control LO GC (Invitrogen) using Lipofectamine ${ }^{\mathrm{TM}}$ RNAiMAX (Invitrogen) and returned to the normoxic incubator. The next day, myotubes were exposed to hypoxia, or kept in normoxia. Medium was replaced $48 \mathrm{~h}$ after transfection and cells were harvested $24 \mathrm{~h}$ later.

\subsection{Transient overexpression of PPAR/PGC-1 $\alpha$ protein}

To disentangle through which molecule hypoxia exerts its effect on PPAR transcriptional activity, myoblasts were transiently transfected with expression plasmids encoding PPAR $\alpha$, PPAR $\delta$ and PGC- $1 \alpha$ protein, which were kindly provided by Dr. Marc van Bilsen (Maastricht University). Stimulation of PPAR transcriptional activity by these

Table 2

qRT-PCR primer details for genes of interest.

\begin{tabular}{|c|c|c|c|c|c|}
\hline Symbol & Name & Ensembl ID & $\begin{array}{l}\text { Forward primer } \\
\left(5^{\prime} \rightarrow 3^{\prime}\right)\end{array}$ & $\begin{array}{l}\text { Reverse primer } \\
\left(5^{\prime} \rightarrow 3^{\prime}\right)\end{array}$ & $\begin{array}{l}\text { Amplicon } \\
\text { size (bp) }\end{array}$ \\
\hline Cox5a & Cytochrome c oxidase subunit Va & ENSMUSG00000000088 & TGCGAGCATGTAGACCGTTAAAT & GAGGTCCTGCTTTGTCCTTAACA & 77 \\
\hline Cyc1 & Cytochrome $c-1$ & ENSMUSG00000022551 & GCATTCGGAGGGGTTTCCAG & CCGCATGAACATCTCCCCA & 176 \\
\hline Esrra & Estrogen-related receptor alpha & ENSMUSG00000024955 & GGCGGACGGCAGAAGTACAAA & GCGACACCAGAGCGTTCAC & 130 \\
\hline Gabpa & $\begin{array}{l}\text { GA binding protein alpha; } \\
\text { nuclear respiratory factor } 2 \text { alpha }\end{array}$ & ENSMUSG00000008976 & TGCTGCACTGGAAGGCTACA & TTACCCAAACCACCCAATGC & 104 \\
\hline Hif-1a & Hypoxia inducible factor 1 alpha & ENSMUSG00000021109 & AATGAAGTGCACCCTAACAAGCCG & TGGCCCGTGCAGTGAAGC & 81 \\
\hline$H k 2$ & Hexokinase II & ENSMUSG00000000628 & AACCTCAAAGTGACGGTGGGC & AAGGACACGTCACATTTCGGAGC & 113 \\
\hline Hmox1 & Heme oxygenase 1 & ENSMUSG00000005413 & AAGCCGAGAATGCTGAGTTCATGA & GGCCGTGTAGATATGGTACAAGGAAG & 101 \\
\hline Myh1 & Myosin heavy chain 1 (type IIx isoform) & ENSMUSG00000056328 & GACAAACTGCAATCAAAGG & TTGGTCACTTTCCTGCACTT & 231 \\
\hline Myh2 & Myosin heavy chain 2 (type Ila isoform) & ENSMUSG00000033196 & CGATGATCTTGCCAGTAATG & ATAACTGAGATACCAGCG & 221 \\
\hline Myh4 & Myosin heavy chain 4 (type IIb isoform) & ENSMUSG00000057003 & AGGGCGGCGGTGGAA & TGGGAATGAGGCATCTGACAA & 141 \\
\hline Myh7 & Myosin heavy chain 7 (type I isoform) & ENSMUSG00000053093 & CAGATCGGGAGAATCAGTCCAT & AGCAAAATATTGGATGACCCTCTTA & 89 \\
\hline Ndufb5 & $\begin{array}{l}\text { NADH dehydrogenase (ubiquinone) } \\
1 \text { beta subcomplex } 5\end{array}$ & ENSMUSG00000027673 & CATCCCTGAACACTGGGAGTA & ССTTTAACCGTAACTCAGCCTTT & 143 \\
\hline Nrf1 & Nuclear respiratory factor 1 & ENSMUSG00000058440 & AGCCACATTGGCTGATGCTT & GGTCATTTCACCGCCCTGTA & 124 \\
\hline Ppara & Peroxisome proliferator-activated receptor alpha & ENSMUSG00000022383 & ACTACGGAGTTCACGCATGTG & TTGTCGTACACCAGCTTCAGC & 76 \\
\hline Ppard & Peroxisome proliferator-activated receptor delta & ENSMUSG00000002250 & AGGCCCGGAGCATCCTCA & TGGATGACAAAGGGTGCGTTG & 55 \\
\hline Ppargc1a & $\begin{array}{l}\text { Peroxisome proliferator-activated receptor } \\
\text { gamma coactivator } 1 \text { alpha }\end{array}$ & ENSMUSG00000029167 & CAACAATGAGCCTGCGAACA & CTTCATCCACGGGGAGACTG & 104 \\
\hline Ppargc1b & $\begin{array}{l}\text { Peroxisome proliferator-activated receptor } \\
\text { gamma coactivator } 1 \text { beta }\end{array}$ & ENSMUSG00000033871 & ACCCTGAGAAAGCGCAATGA & CCCAGATGAGGGAAGGGACT & 120 \\
\hline$S d h b$ & Succinate dehydrogenase complex, subunit B & ENSMUSG00000009863 & AATTTGCCATTTACCGATGGGA & AGCATCCAACACCATAGGTCC & 104 \\
\hline Slc2a1 & Glucose transporter (GLUT) 1 & ENSMUSG00000028645 & TGACCATCGCCCTGGCCT & GGACCAGGGCCTACTTCAAAGAAG & 103 \\
\hline Tfam & Mitochondrial transcription factor A & ENSMUSG00000003923 & CCGGCAGAGACGGTTAAAAA & TCATCCTTTGCCTCCTGGAA & 129 \\
\hline Vegfa & Vascular endothelial growth factor A & ENSMUSG00000023951 & CTGTACCTCCACCATGCCAAGT & TCGCTGGTAGACATCCATGAACT & 99 \\
\hline
\end{tabular}


expression plasmids has previously been shown in C2C12 myoblasts [35]. Myoblasts were plated at a density of 30\% and allowed to attach overnight. The next day, the cells were transfected with plasmids encoding murine PPAR $\alpha(\mathrm{mPPAR} \alpha), \mathrm{PGC}-1 \alpha(\mathrm{mPGC} 1 \alpha)$ or rat PPAR $\delta$ (rPPAR $\delta$ ) or empty vector ( $\mathrm{pCDNA3.1+}$, Invitrogen) combined with a vector expressing $\beta$-gal using PfU Nanofectin (PAA Laboratories). For luciferase assays, the PPAR reporter plasmid was cotransfected. After a two-hour incubation period, growth medium was replaced and dishes were replaced to the hypoxic incubator or kept in normoxia. Cells were harvested $24 \mathrm{~h}$ later. Luciferase activities were corrected for $\beta$ gal activity to control for differences in transfection efficiencies.

\subsection{Statistical analyses}

Data were analyzed using IBM SPSS Statistics 21.0 (IBM Corp., Armonk, NY). Differences between samples exposed to hypoxia or $\mathrm{CoCl}_{2}$ and those exposed to normoxia were tested using the Mann-Whitney test. Data are presented by mean + SD. A two-tailed $p$-value $<0.05$ was considered statistically significant.

\section{Results}

3.1. Hypoxia impairs muscle oxidative capacity and the regulatory PPAR/ PGC-1 $\alpha$ pathway

To study the effect of hypoxia on the markers of oxidative capacity, myotubes were exposed to hypoxia $\left(4 \% \mathrm{O}_{2}\right)$ for three days. This resulted in significantly decreased protein content of the oxidative phosphorylation (OXPHOS) complex III and V subunits (Fig. 1A). Reduced OXPHOS protein content was associated with lower gene expression levels of OXPHOS subunits from complexes I to IV (Fig. 1B). At the same time, gene expression of the glycolytic enzyme hexokinase-II was significantly increased by hypoxia.

To investigate how regulators of mitochondrial biogenesis and oxidative phenotype are affected by hypoxia, we measured the gene expression levels of PPAR $\alpha$, PPAR $\delta$, PGC $-1 \alpha$, PGC- $1 \beta$, Tfam, ERR $\alpha$, NRF- 1 and NRF- $2 \alpha$. In response to hypoxia, the gene expression levels of PPAR $\alpha$, PPAR $\delta$, PGC- $1 \alpha$, PGC- $1 \beta$ and ERR $\alpha$ were markedly decreased. Levels of NRF- 1 and NRF- $2 \alpha$ were increased, whereas Tfam expression levels were unchanged (Fig. 1C). It is worth mentioning that the expression of Tfam was significantly decreased after $24 \mathrm{~h}$ exposure to hypoxia, indicating that hypoxia reduced Tfam gene expression in a more transient fashion. As a functional signaling outcome measure, we assessed PPAR transcriptional activity using the PPAR luciferase reporter cell line and found it to be substantially decreased by hypoxia (Fig. 1D). Hypoxia-induced increased PPAR $\gamma$ expression (data not shown) suggests that the reduced PPAR transcriptional activity probably reflects decreased PPAR $\alpha$ or PPAR $\delta$ activity.

\subsection{Hypoxia shifts muscle towards oxidative fiber-type I profile}

To assess whether exposure to hypoxia induces a shift from oxidative towards a more glycolytic fiber-type profile, we determined the protein content and mRNA levels of the respective myosin heavy chain (MyHC) isoforms in myotubes exposed to $4 \%$ oxygen for three days. Protein content of the slow oxidative type I MyHC isoform was markedly increased, while content of fast isoforms was reduced under hypoxic conditions (Fig. 2A). mRNA levels of oxidative type I and type



A

c

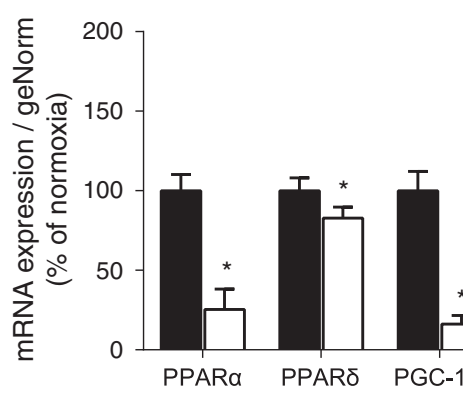

\section{B}

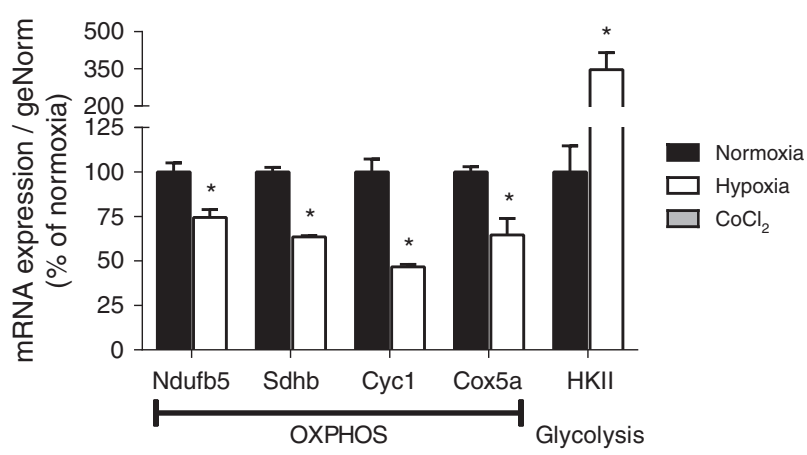

D

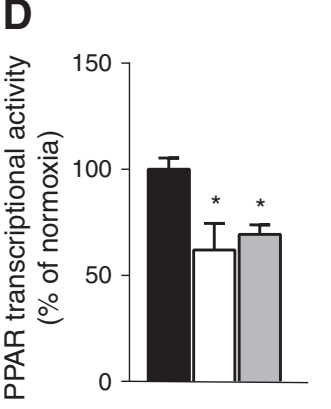

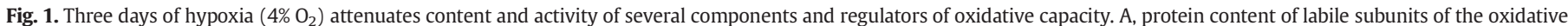

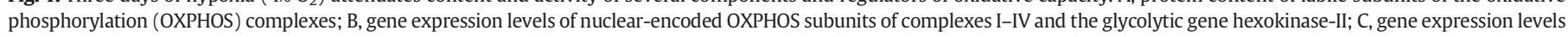

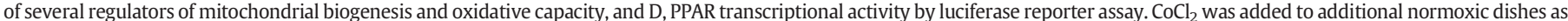

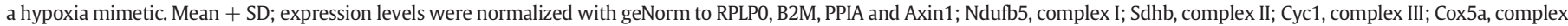

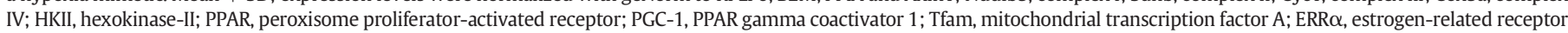
$\alpha$; NRF, nuclear respiratory factor. Experiments were performed in triplicate; ${ }^{*} p<0.05$ compared to normoxic control. 



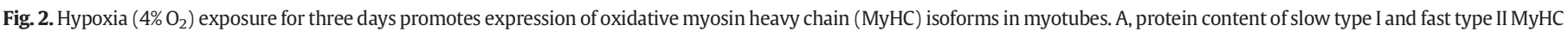
isoforms and B, gene expression of MyHC isoforms. Mean + SD. Experiments were performed in triplicate; ${ }^{*} p<0.05$ compared to normoxic control.

IIa MyHC were significantly increased, which was associated with a reduction of MyHC type IIx and IIb mRNA levels (Fig. 2B).

\subsection{Hypoxia induces HIF- $1 \alpha$ transcriptional activity and stimulates glycolytic metabolism in muscle}

HIF transcriptional activity was measured in C2C12 cells that were transfected with a plasmid carrying a luciferase gene under control of HIF-responsive elements. Myoblasts transiently transfected with the HIF reporter plasmid were exposed to $1 \%, 2 \%, 4 \%$ and $21 \%$ oxygen for $24 \mathrm{~h}$. HIF luciferase reporter activity was strongly induced by lower oxygen concentrations (Fig. 3A). At $4 \% \mathrm{O}_{2}$ HIF activation was still evident. This oxygen level also has negligible effects on myotube morphology and viability, indicating that this condition was most suitable for our experiments. To validate whether the hypoxic response was physiologically intact, we determined the mRNA expression levels of HIF-regulated genes in myotubes after three days of $4 \%$ oxygen exposure. Levels of VEGF-A, GLUT1 and HO1 were significantly increased in the hypoxic myotubes (Fig. 3B).

In addition to HIF- $1 \alpha$, two other HIF $\alpha$ isoforms, HIF- $2 \alpha$ and HIF- $3 \alpha$, have been described to mediate the hypoxic response. To confirm that the HIF luciferase reporter mainly reflects HIF- $1 \alpha$ transcriptional activity, myotubes stably carrying the HIF luciferase reporter were transiently transfected with siRNA targeting HIF-1 $\alpha$. The HIF- $1 \alpha$
A
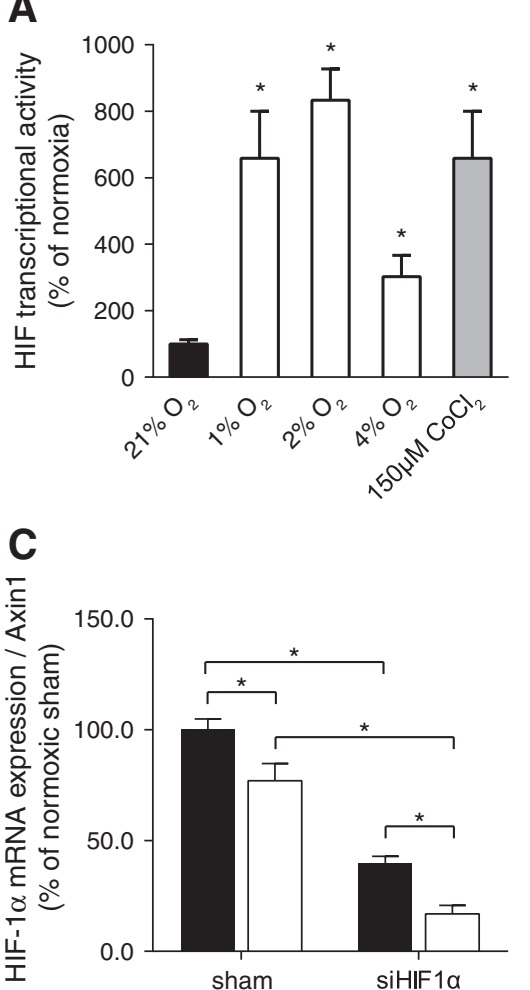
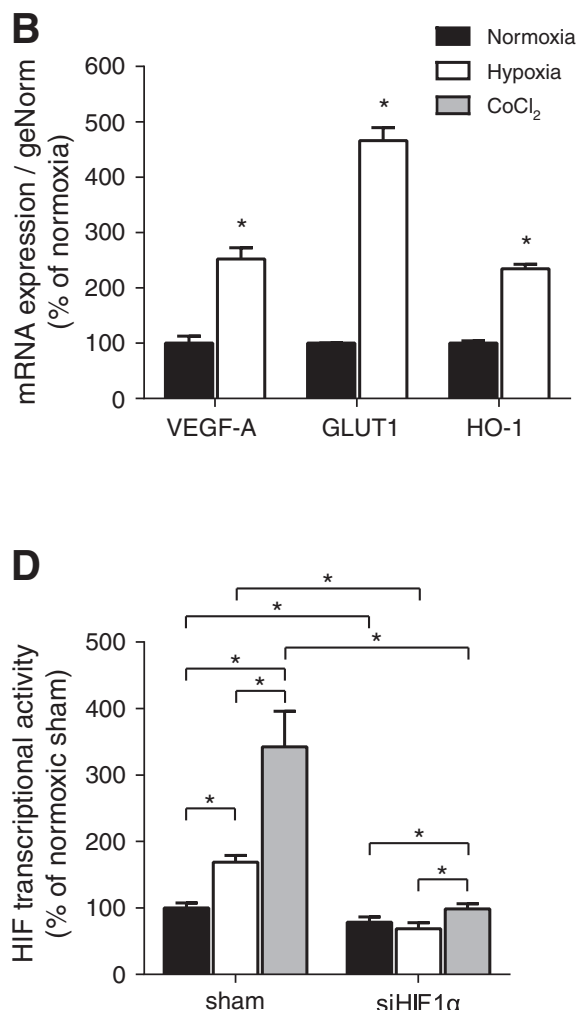



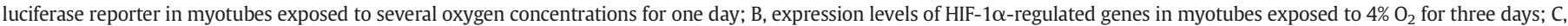

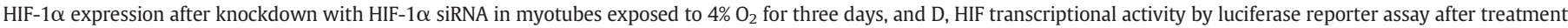

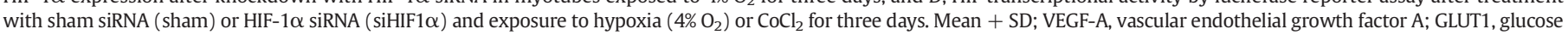
transporter 1; HO-1, heme oxygenase 1. Experiments were performed in triplicate; ${ }^{*} p<0.05$ compared to normoxic control or for the comparison indicated by the horizontal line. 
siRNA reduced the expression of the HIF- $1 \alpha$ gene by $60-80 \%$ (Fig. 3C) and more importantly, it completely abrogated the hypoxia-induced increase of HIF luciferase reporter activity (Fig. 3D).

\subsection{Differential regulation of oxidative phenotype components is HIF- $1 \alpha$-dependent}

To assess the role of HIF- $1 \alpha$ in the hypoxia-induced changes of muscle oxidative phenotype, levels of markers of oxidative phenotype were determined in myotubes transiently transfected with the HIF- $1 \alpha$ siRNA. Knockdown of HIF- $1 \alpha$ gene expression resulted in significant preservation of the protein content of the OXPHOS complex V subunit (Fig. 4A). A similar but less pronounced effect was observed for OXPHOS genes (data not shown), which corroborates that impairment of oxidative phenotype occurs at the transcriptional level. Gene expression levels of the transcription factors PPAR $\alpha$, PPAR $\delta$, and ERR $\alpha$ and their coregulators PGC- $1 \alpha$ and PGC- $1 \beta$ were significantly reduced by hypoxia, however HIF- $1 \alpha$ knockdown could only restore levels of PPAR $\delta$ and PGC-1 $\alpha$ (Fig. 4B). Moreover, HIF-1 $\alpha$ knockdown in hypoxia restored PPAR transcriptional activity to normoxic levels (Fig. 4C). Together, these data suggest that PPAR $\delta$ or PGC- $1 \alpha$ could be the mediator in hypoxia-induced impairment of PPAR transcriptional activity.

Transient knockdown of HIF-1 $\alpha$ expression resulted in attenuation or even abrogation of hypoxia-stimulated MyHC type I gene expression, but did not significantly affect the expression of the MyHC type II isoforms (Fig. 4D).
3.5. Hypoxia-associated attenuation of PPAR transcriptional activity is mediated through PGC- $1 \alpha$

To assess whether synthetic stimulation could abolish the effect of hypoxia on PPAR transcriptional activity and identify PPAR $\delta$ or PGC- $1 \alpha$ as the key factor, we investigated the influence of liganddependent PPAR $\delta$ activation and PPAR $\delta / P G C-1 \alpha$ overexpression on PPAR transcriptional activity under hypoxic conditions. PPAR luciferase reporter activity was reduced by hypoxia to a similar extent in the absence and presence of GW501516, a specific PPAR $\delta$ ligand (Fig. 5A). However, by adding the PPAR ligand PPAR transcriptional activity in hypoxia could be normalized to levels similar to basal PPAR transcriptional activity in normoxia.

Because myotubes are refractive to lipid-based transfection with plasmids, undifferentiated myoblasts were transfected with the PPAR luciferase reporter plasmid in combination with overexpression plasmids encoding either PPAR $\delta$, PPAR $\alpha$ or PGC- $1 \alpha$. In myoblasts, PPAR transcriptional activity was markedly reduced after 2 days of exposure to hypoxia. Overexpression of PGC- $1 \alpha$ radically increased PPAR transcriptional activity 14 -fold and this was not attenuated by hypoxia (Fig. 5B). Overexpression of PPAR $\delta$ resulted in a modest 4-fold induction of PPAR transcriptional activity, but this effect was reduced by $25 \%$ under hypoxic conditions. PPAR $\alpha$ overexpression stimulated PPAR transcriptional activity 17 -fold, with a hypoxia-associated reduction of this effect by $18 \%$. Overexpression of PGC- $1 \alpha$ did not modify the expression levels of PPAR $\alpha$ and PPAR $\delta$ (Fig. 5C). Together with the reduced sensitivity of the PPAR luciferase reporter to hypoxia in the presence
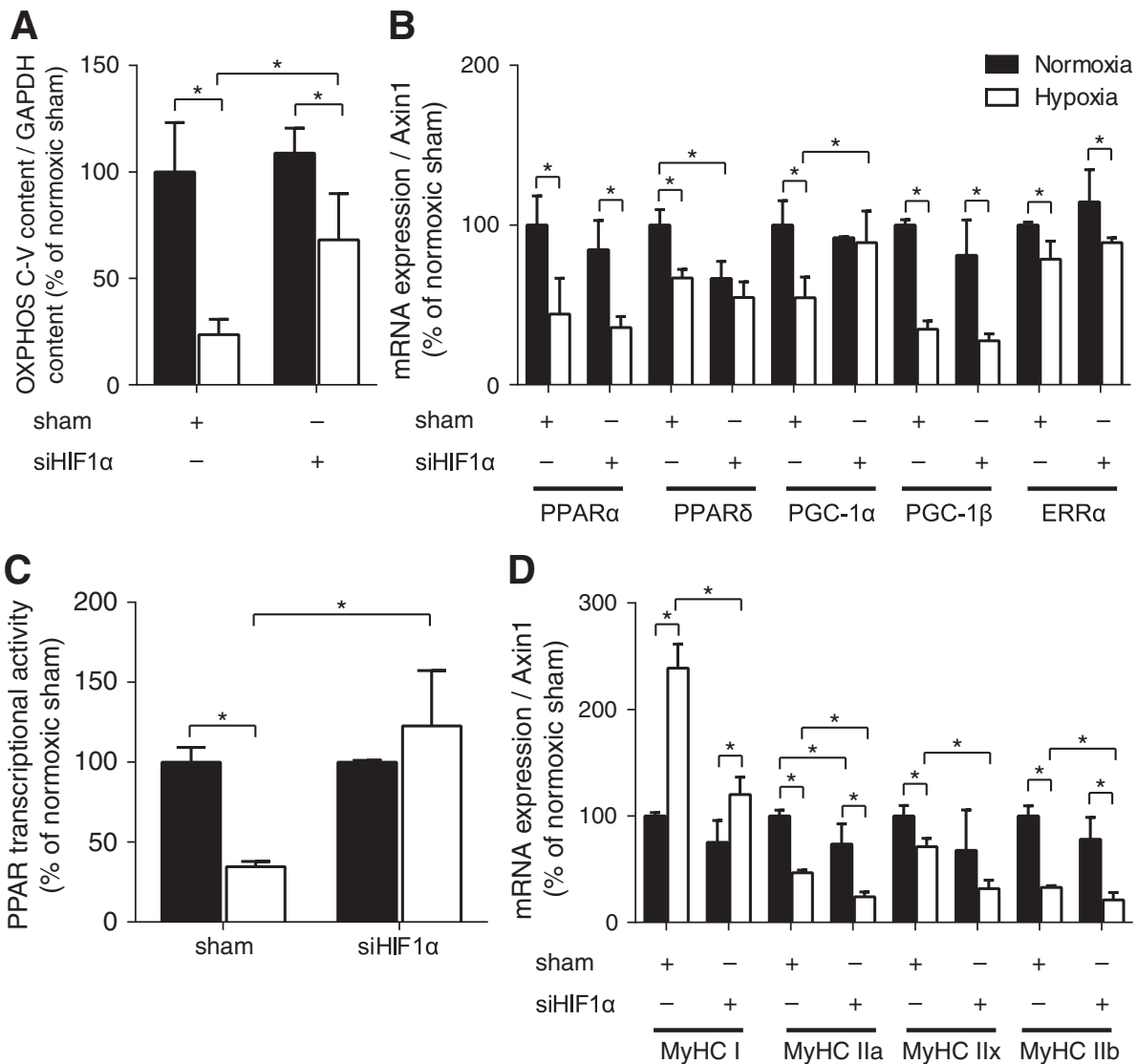



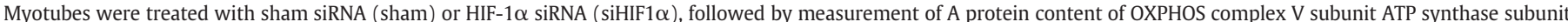

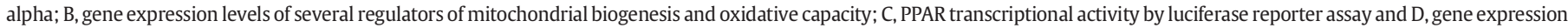

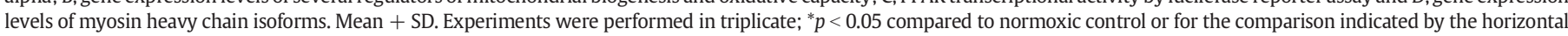
line. 



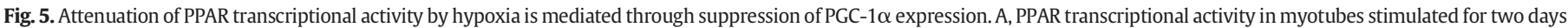

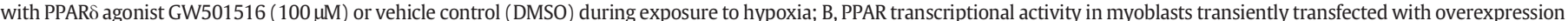



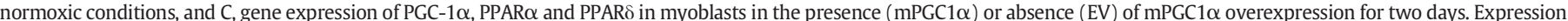

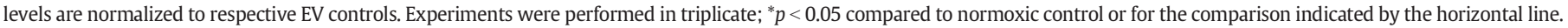

of PGC- $1 \alpha$ overexpression, this identifies PGC- $1 \alpha$ as the likely mediator of hypoxia-associated attenuation of PPAR transcriptional activity and muscle oxidative phenotype.

\section{Discussion}

In this study we showed that hypoxia differentially regulates muscle oxidative phenotype by directly downregulating oxidative capacity through HIF- $1 \alpha$ and PGC- $1 \alpha$ and simultaneously stimulating oxidative myosin heavy chain type I levels, also in a HIF- $1 \alpha$-dependent manner. This suggests a segregation of the regulation of oxidative metabolism and structural muscle proteins under hypoxic conditions.

HIF-1 activity is progressively stimulated by decreasing oxygen concentrations and was found to be an essential mediator of oxygen homeostasis [36]. It has been shown that HIF-1 $\alpha$ stimulates muscle glycolytic phenotype [22] and HIF-1 $\alpha$ knockout modestly improves muscle oxidative phenotype [23]. However, these experiments were performed in vivo and do not provide insight into the direct regulation of muscle oxidative phenotype by HIF- $1 \alpha$. Therefore, we assessed the role of HIF- $1 \alpha$ in downregulation of muscle oxidative phenotype by hypoxia. Indeed, we found significant stimulation of HIF transcriptional activity in our model of hypoxia-exposed myotubes. Our group recently showed that activation of NF- $\kappa B$ by TNF- $\alpha$ impairs muscle oxidative phenotype [35]. However, using the same NF- $\kappa B$ responsive luciferase reporter construct we did not find increased activation of NF- $\kappa$ B by hypoxia in $\mathrm{C} 2 \mathrm{C} 12$ myotubes (data not shown). Further experiments were therefore focused on modulation of HIF-1 $\alpha$.

PPAR $\alpha$, PPAR $\delta$, PGC $-1 \alpha$, PGC- $1 \beta$ and ERR $\alpha$ are important regulators of oxidative capacity. Hypoxia generally reduced the gene expression levels of all these markers. In addition, hypoxia markedly decreased
PPAR transcriptional activity. The PPAR reporter we used is responsive to agonists for PPAR $\alpha$, PPAR $\delta$ and PPAR $\gamma$ [37] and might thus be indirectly affected by PGC $-1 \alpha$ and PGC- $1 \beta$ via coactivation of these PPARs [38]. Restoration of both PPAR transcriptional activity and gene expression levels of PPAR $\delta$ and PGC- $1 \alpha$ by HIF- $1 \alpha$ knockdown suggests that HIF- $1 \alpha$ mediates the reduced PPAR transcriptional activity via either PPAR $\delta$ or PGC- $1 \alpha$. However, only overexpression of PGC- $1 \alpha$ could prevent hypoxia-associated depression of PPAR transcriptional activity with no associated changes in PPAR $\delta$ gene expression. It should be noted that the overexpression studies were performed in myoblasts rather than in myotubes, because of the technical limitation of myotubes to be transfected with expression plasmids using lipid-based techniques. However, also in untransfected myoblasts PGC- $1 \alpha$ expression was reduced by hypoxia (data not shown).

A central role for PGC- $1 \alpha$ in hypoxia-induced impairment of oxidative capacity is further supported by the observation that HIF- $1 \alpha$ knockdown could successfully restore OXPHOS subunit V content and OXPHOS gene expression. Regulation of OXPHOS expression levels is mediated largely through PGC- $1 \alpha[26]$ and whole-body PGC- $1 \alpha$ knockout experiments in mice have shown that skeletal muscle expression of OXPHOS genes is markedly blunted in the absence of PGC-1 $\alpha$ [39].

A potential mechanism by which PGC- $1 \alpha$ expression is negatively modulated by hypoxia is via histone deacetylases (HDACs). Ramjiawan et al. showed in hypoxic cardiomyocytes that histone 3 lysine 9 (H3K9) acetylation was significantly reduced in the PGC- $1 \alpha$ promoter region, which resulted in reduced PGC- $1 \alpha$ expression [40]. Blocking HDAC activity abolished this hypoxia-induced loss of PGC- $1 \alpha$. Seo et al. showed that HDAC4, -5 and -7 promote HIF- $1 \alpha$ transactivation under hypoxic conditions [41], whereas HDAC inhibitors inhibit HIF-1 $\alpha$ activity [42]. We previously showed that skeletal muscle of patients with COPD, a 
disease associated with hypoxia, is characterized by a decreased gene expression of PGC-1 $\alpha$ and OXPHOS protein content [43], which is in line with the results from the current study. Interestingly, in a different study, HDAC4 protein content was shown to be increased in the quadriceps muscle of patients with COPD compared to healthy controls [44]. Moreover, a systems biology approach comparing muscle biopsies from patients with COPD and muscle tissue from mice exposed to chronic hypoxia, identified hypoxia as a key factor in the muscle abnormalities in COPD, associated with increased HDAC expression [3].

It is of interest that supplementation of the muscle cells under hypoxia with the selective PPAR $\delta$ agonist GW501516 restored PPAR transcriptional activity to normoxic levels. Although decreased PGC- $1 \alpha$ turned out to be most important for attenuation of PPAR transcriptional activity under hypoxic conditions, PPAR $\delta$ seems a promising target for therapeutic intervention.

In contrast to what we expected, hypoxia induced rather than inhibited the expression of the oxidative myosin heavy chain (MyHC) type I gene and protein. Moreover, HIF- $1 \alpha$ knockdown experiments showed that MyHC type I induction was HIF-1 $\alpha$-dependent, unlike the changes in gene expression levels of the other MyHC genes.

A role for PGC- $1 \alpha$ in the hypoxia-associated increase of MyHC type I expression is unlikely, because muscle-specific PGC- $1 \alpha$ knockout mice present with a fiber-type shift towards glycolytic rather than oxidative fibers [45]. Moreover, transgenic mice that overexpress PGC- $1 \alpha$ in the muscle are characterized by an increased proportion of type I fibers [46].

Interestingly, in cardiomyocytes a similar response of MyHC type I (also known as $\beta$-myosin in the heart) to hypoxia was observed [47]. To our knowledge, only one paper reports on myosin heavy chain composition in $\mathrm{C} 2 \mathrm{C} 12$ cells in relation to HIF- $1 \alpha$, showing that HIF- $1 \alpha$ overexpression stimulated the expression of MyHC IIb and reduced MyHC I [22], although increased HIF-1 $\alpha$ transcriptional activity was not confirmed in this study. However, these cells were still in a differentiating phase, whereas our C2C12 cells were fully differentiated when exposed to hypoxia. Ishihara et al. showed that the effect of hypoxia on fiber-type composition was indeed dependent on the developmental stage of the rats exposed to hypoxia [48]. Nevertheless, the hypoxia-associated increase of oxidative MyHC isoforms that we found seems counterintuitive, because the type I fibers rely primarily on oxidative energy metabolism for muscle contraction. Possibly, the absence of contraction and extramuscular factors such as nerve stimulation or hormones, results in uncoupling of the regulation of MyHC profile and oxidative capacity.

\section{Conclusions}

Our results indicate that hypoxia could explain the loss of oxidative capacity as observed in the muscles of for example patients with COPD or CHF. However, the frequently co-occurring I-to-II fiber-type shift is possibly caused or overruled by factors other than direct hypoxia.

Our data furthermore suggests that the PPAR/PGC- $1 \alpha$ pathway would be an interesting target for pharmacological modulation to treat disease-related loss of oxidative capacity. An intervention study by Broekhuizen et al. indeed showed a significant improvement of exercise capacity in COPD patients who received nutritional supplementation with PPAR-activating poly-unsaturated fatty acids (PUFAs) in addition to the effect of exercise training [49]. Although no information was available on changes in skeletal muscle oxidative capacity, it can be speculated that the PUFA-induced improvement in exercise capacity was mediated by an improved muscle oxidative capacity. Further studies should focus on the effect of PUFA supplementation on muscle oxidative capacity under hypoxic conditions to explore PUFA supplementation as a therapy for hypoxiaassociated loss of muscle oxidative phenotype.

\section{Author contributions}

IS, AS, BV, and HG were involved in conception and design of the research; IS, BV, and MK performed the experiments; IS and BV analyzed the data; IS, AS, and HG interpreted the results of the experiments; IS prepared the figures and drafted the manuscript; AS and HG edited and revised the manuscript; and IS, AS, BV, MK and HG approved the final version of the manuscript.

\section{Acknowledgments}

This project was supported by The Netherlands Asthma Foundation Award \#3.2.05.038 and by the Transnational University Limburg (tTUL). These funders had no role in study design, in data collection, analysis and interpretation, in manuscript preparation, or in the decision to publish.

\section{References}

[1] H.R. Gosker, E.F. Wouters, G.J. van der Vusse, A.M. Schols, Am. J. Clin. Nutr. 71 (2000) 1033-1047.

[2] C. de Theije, F. Costes, R.C. Langen, C. Pison, H.R. Gosker, Curr. Opin. Clin. Nutr. Metab. Care 14 (2011) 548-553.

[3] N. Turan, S. Kalko, A. Stincone, K. Clarke, A. Sabah, K. Howlett, S.J. Curnow, D.A Rodriguez, M. Cascante, L. O'Neill, S. Egginton, J. Roca, F. Falciani, PLoS Comput. Biol. 7 (2011) e1002129.

[4] S.D. Katz, C. Maskin, G. Jondeau, T. Cocke, R. Berkowitz, T. LeJemtel, J. Appl. Physiol 2000 (88) (1985) 2138-2142.

[5] K.A. Webster, J. Exp. Biol. 206 (2003) 2911-2922.

[6] H.R. Gosker, N.H. Lencer, F.M. Franssen, G.J. van der Vusse, E.F. Wouters, A.M. Schols, Chest 123 (2003) 1416-1424

[7] H. Takahashi, K. Asano, H. Nakayama, Appl. Human Sci. 15 (1996) 111-114.

[8] K. Itoh, T. Moritani, K. Ishida, C. Hirofuji, S. Taguchi, M. Itoh, Eur. J. Appl. Physiol. Occup. Physiol. 60 (1990) 331-336.

[9] M. Faucher, C. Guillot, T. Marqueste, N. Kipson, M.H. Mayet-Sornay, D. Desplanches, Y. Jammes, M. Badier, Pflugers Arch. 450 (2005) 45-52.

[10] S. De Palma, M. Ripamonti, A. Vigano, M. Moriggi, D. Capitanio, M. Samaja, G. Milano, P. Cerretelli, R. Wait, C. Gelfi, J. Proteome Res. 6 (2007) 1974-1984.

[11] H. Takahashi, K. Kikuchi, H. Nakayama, Ann. Physiol. Anthropol. 12 (1993) 363-369.

[12] U. Boutellier, H. Howald, P.E. di Prampero, D. Giezendanner, P. Cerretelli, Prog. Clin. Biol. Res. 136 (1983) 273-285.

[13] H. Howald, D. Pette, J.A. Simoneau, A. Uber, H. Hoppeler, P. Cerretelli, J. Int, Sports Med. 11 (Suppl. 1) (1990) S10-S14.

[14] A. Abdelmalki, S. Fimbel, M.H. Mayet-Sornay, B. Sempore, R. Favier, Pflugers Arch. 431 (1996) 671-679.

[15] A.H. Sillau, N. Banchero, Pflugers Arch. 370 (1977) 227-232.

[16] A.X. Bigard, H. Sanchez, O. Birot, B. Serrurier, J. Appl. Physiol. 2000 (88) (1985) 479-486.

[17] H.J. Green, J.R. Sutton, A. Cymerman, P.M. Young, C.S. Houston, J. Appl. Physiol. 1989 (66) (1985) 2454-2461.

[18] H. Hoppeler, E. Kleinert, C. Schlegel, H. Claassen, H. Howald, S.R. Kayar, P. Cerretelli, J Int. Sports Med. 11 (Suppl. 1) (1990) S3-S9.

[19] H. Hoppeler, D. Desplanches, J. Int. Sports Med. 13 (Suppl. 1) (1992) S166-S168.

[20] I. Papandreou, R.A. Cairns, L. Fontana, A.L. Lim, N.C. Denko, Cell Metab. 3 (2006) 187-197.

[21] J.W. Kim, I. Tchernyshyov, G.L. Semenza, C.V. Dang, Cell Metab. 3 (2006) 177-185.

[22] I.G. Lunde, S.L. Anton, J.C. Bruusgaard, Z.A. Rana, S. Ellefsen, K. Gundersen, J. Physiol. 589 (2011) 1443-1454.

[23] S.D. Mason, R.A. Howlett, M.J. Kim, I.M. Olfert, M.C. Hogan, W. McNulty, R.P. Hickey, P.D. Wagner, C.R. Kahn, F.J. Giordano, R.S. Johnson, PLoS Biol. 2 (2004) e288.

[24] J. Bastin, F. Aubey, A. Rotig, A. Munnich, F. Djouadi, J. Clin. Endocrinol. Metab. 93 (2008) 1433-1441.

[25] Z. Wu, P. Puigserver, U. Andersson, C. Zhang, G. Adelmant, V. Mootha, A. Troy, S. Cinti, B. Lowell, R.C. Scarpulla, B.M. Spiegelman, Cell 98 (1999) 115-124.

[26] V.K. Mootha, C. Handschin, D. Arlow, X. Xie, J. St Pierre, S. Sihag, W. Yang, D. Altshuler, P. Puigserver, N. Patterson, P.J. Willy, I.G. Schulman, R.A. Heyman, E.S. Lander, B.M. Spiegelman, Proc. Natl. Acad. Sci. U. S. A. 101 (2004) 6570-6575.

[27] S.N. Schreiber, R. Emter, M.B. Hock, D. Knutti, J. Cardenas, M. Podvinec, E.J. Oakeley, A. Kralli, Proc. Natl. Acad. Sci. U. S. A. 101 (2004) 6472-6477.

[28] A.H. Remels, P. Schrauwen, R. Broekhuizen, J. Willems, S. Kersten, H.R. Gosker, A.M. Schols, Eur. Respir. J. 30 (2007) 245-252.

[29] G. Vescovo, B. Ravara, V. Gobbo, A. Angelini, L. Dalla Libera, Int. J. Cardiol. 104 (2005) 298-306.

[30] T. Shibata, A.J. Giaccia, J.M. Brown, Gene Ther. 7 (2000) 493-498.

[31] J.M. Brandt, F. Djouadi, D.P. Kelly, J. Biol. Chem. 273 (1998) 23786-23792.

[32] R.A. Rupec, P.A. Baeuerle, Eur. J. Biochem. 234 (1995) 632-640.

[33] P. Flicek, M.R. Amode, D. Barrell, K. Beal, K. Billis, S. Brent, D. Carvalho-Silva, P. Clapham, G. Coates, S. Fitzgerald, L. Gil, C.G. Giron, L. Gordon, T. Hourlier, S. Hunt, N. Johnson, T. Juettemann, A.K. Kahari, S. Keenan, E. Kulesha, F.J. Martin, T. Maurel, W.M. McLaren, D.N. Murphy, R. Nag, B. Overduin, M. Pignatelli, B. Pritchard, E. 
Pritchard, H.S. Riat, M. Ruffier, D. Sheppard, K. Taylor, A. Thormann, S.J. Trevanion, A. Vullo, S.P. Wilder, M. Wilson, A. Zadissa, B.L. Aken, E. Birney, F. Cunningham, J. Harrow, J. Herrero, T.J. Hubbard, R. Kinsella, M. Muffato, A. Parker, G. Spudich, A Yates, D.R. Zerbino, S.M. Searle, Nucleic Acids Res. 42 (2014) D749-D755.

[34] J. Vandesompele, K. De Preter, F. Pattyn, B. Poppe, N. Van Roy, A. De Paepe, F. Speleman, Genome Biol. 3 (2002) (RESEARCH0034).

[35] A.H. Remels, H.R. Gosker, P. Schrauwen, P.P. Hommelberg, P. Sliwinski, M. Polkey, J. Galdiz, E.F. Wouters, R.C. Langen, A.M. Schols, FASEB J. 24 (2010) 5052-5062.

[36] G.L. Semenza, J. Appl. Physiol. 2000 (88) (1985) 1474-1480.

[37] A.H. Remels, R.C. Langen, H.R. Gosker, A.P. Russell, F. Spaapen, J.W. Voncken, P. Schrauwen, A.M. Schols, Am. J. Physiol. Endocrinol. Metab. 297 (2009) E174-E183.

[38] N. Viswakarma, Y. Jia, L. Bai, A. Vluggens, J. Borensztajn, J. Xu, J.K. Reddy, PPAR Res. 2010 (2010)

[39] Z. Arany, H. He, J. Lin, K. Hoyer, C. Handschin, O. Toka, F. Ahmad, T. Matsui, S. Chin, P.H. Wu, I.I. Rybkin, J.M. Shelton, M. Manieri, S. Cinti, F.J. Schoen, R. Bassel-Duby, A Rosenzweig, J.S. Ingwall, B.M. Spiegelman, Cell Metab. 1 (2005) 259-271.

[40] A. Ramjiawan, R.A. Bagchi, A. Blant, L. Albak, M.A. Cavasin, T.R. Horn, T.A. McKinsey, M.P. Czubryt, Am. J. Physiol. Cell Physiol. 304 (2013) C1064-C1072.

[41] H.W. Seo, E.J. Kim, H. Na, M.O. Lee, FEBS Lett. 583 (2009) 55-60.
[42] D.Z. Qian, S.K. Kachhap, S.J. Collis, H.M. Verheul, M.A. Carducci, P. Atadja, R. Pili, Cancer Res. 66 (2006) 8814-8821.

[43] B. van den Borst, I.G. Slot, V.A. Hellwig, B.A. Vosse, M.C. Kelders, E. Barreiro, A.M. Schols, H.R. Gosker, J. Appl. Physiol. 2013 (114) (1985) 1319-1328.

[44] A. Lewis, J. Riddoch-Contreras, S.A. Natanek, A. Donaldson, W.D. Man, J. Moxham, N.S. Hopkinson, M.I. Polkey, P.R. Kemp, Thorax 67 (2012) 26-34.

[45] C. Handschin, S. Chin, P. Li, F. Liu, E. Maratos-Flier, N.K. Lebrasseur, Z. Yan, B.M. Spiegelman, J. Biol. Chem. 282 (2007) 30014-30021.

[46] J. Lin, H. Wu, P.T. Tarr, C.Y. Zhang, Z. Wu, O. Boss, L.F. Michael, P. Puigserver, E. Isotani, E.N. Olson, B.B. Lowell, R. Bassel-Duby, B.M. Spiegelman, Nature 418 (2002) 797-801

[47] J. Krishnan, M. Suter, R. Windak, T. Krebs, A. Felley, C. Montessuit, M. TokarskaSchlattner, E. Aasum, A. Bogdanova, E. Perriard, J.C. Perriard, T. Larsen, T. Pedrazzini, W. Krek, Cell Metab. 9 (2009) 512-524.

[48] A. Ishihara, K. Itoh, Y. Oishi, M. Itoh, C. Hirofuji, H. Hayashi, Pflugers Arch. 429 (1995) 601-606.

[49] R. Broekhuizen, E.F. Wouters, E.C. Creutzberg, C.A. Weling-Scheepers, A.M. Schols, Thorax 60 (2005) 376-382. 